\title{
Characteristics of non-conveyed patients in emergency medical services (EMS): a one- year prospective descriptive and comparative study in a region of Sweden
}

Erik Höglund $^{1 *}$ (D), Magnus Andersson-Hagiwara ${ }^{2}$, Agneta Schröder ${ }^{1,3}$, Margareta Möller $^{1}$ and Emma Ohlsson-Nevo ${ }^{1,4}$

\begin{abstract}
Background: There has been an increasing demand for emergency medical services (EMS), and a growing number of patients are not conveyed; i.e., they are referred to levels of care other than ambulance conveyance to the emergency department. Patient safety issues have been raised regarding the ability of EMS to decide not to convey patients. To improve non-conveyance guidelines, information is needed about patients who are not conveyed by EMS. Therefore, the purpose of this study was to describe and compare the proportion and characteristics of nonconveyed EMS patients, together with assignment data.

Methods: A descriptive and comparative consecutive cohort design was undertaken. The decision of whether to convey patients was made by EMS according to a region-specific non-conveyance guideline. Non-conveyed patients' medical record data were prospectively gathered from February 2016 to January 2017. Analyses was conducted using the chi-squared test, two-sample t test, proportion test and Mann-Whitneys U-test.

Results: Out of the 23,250 patients served during the study period, 2691 (12\%) were not conveyed. For nonconveyed adults, the most commonly used Emergency Signs and Symptoms (ESS) codes were unspecific symptoms/malaise, abdomen/flank/groin pain, and breathing difficulties. For non-conveyed children, the most common ESS codes were breathing difficulties and fever of unclear origin. Most of the non-conveyed patients had normal vital signs. Half of all patients with a designated non-conveyance level of care were referred to self-care. There were statistically significant differences between men and women.

Conclusions: Fewer patients were non-conveyed in the studied region compared to national and international non-conveyance rates. The differences seen between men and women were not of clinical significance. Follow-up studies are needed to understand what effect patient outcome so that guidelines might improve.
\end{abstract}

Keywords: Ambulance, Emergency medical services, Non-conveyance, Non-transport, Triage

\footnotetext{
* Correspondence: erik.hoglund@oru.se

'University Health Care Research Center, Faculty of Medicine and Health,

Örebro University, Box 1613, 70116 Örebro, Sweden

Full list of author information is available at the end of the article
}

C C The Author(s). 2020 Open Access This article is licensed under a Creative Commons Attribution 4.0 International License, which permits use, sharing, adaptation, distribution and reproduction in any medium or format, as long as you give appropriate credit to the original author(s) and the source, provide a link to the Creative Commons licence, and indicate if changes were made. The images or other third party material in this article are included in the article's Creative Commons licence, unless indicated otherwise in a credit line to the material. If material is not included in the article's Creative Commons licence and your intended use is not permitted by statutory regulation or exceeds the permitted use, you will need to obtain permission directly from the copyright holder. To view a copy of this licence, visit http://creativecommons.org/licenses/by/4.0/. The Creative Commons Public Domain Dedication waiver (http://creativecommons.org/publicdomain/zero/1.0/) applies to the data made available in this article, unless otherwise stated in a credit line to the data. 


\section{Background}

Both nationally and internationally, the demand for emergency medical services (EMS) has been growing approximately $3-5 \%$ annually [1, 2], and $40-79 \%$ of assessed patients do not need EMS interventions [3-5]. The proportion of patients who are assessed but do not require EMS interventions has also reportedly increased [1]. Because of the increasing demand and the fact that growing numbers of EMS users do not need EMS interventions, an increasing number of patients are left at the scene of the incident without ambulance conveyance to the emergency department (ED) [3, 4].

The growing and changing demand has been attributed to the growing and ageing population [2, 6-8] and to the fact that younger patients, patients with socioeconomic or educational disadvantages, and patients with no pre-existing health conditions contacting EMS at disproportionately high rates $[1,9,10]$. Internationally, non-conveyance rates have been reported to be between 29 and 42\% [4, 7]; in Sweden specifically, published non-conveyance rates vary between 10 and $22 \%$ [10-12].

The decision not to convey a patient has been described by EMS clinicians as a complex process that involves a great deal of responsibility $[11,13,14]$. Informal decision-making processes are predominant [14], and non-conveyance is more common in remote areas than near population centres [11, 15]. Taking ambulance availability into account when choosing not to convey patients from remote areas might jeopardize patient safety, since studies have shown that patients living further away from the hospital present themselves to EMS with more severe conditions than patients living in urban areas close to the hospital [16-18].

When patients are not conveyed, they are assessed with guidelines based on vital signs and levels of urgency [13]. Vital signs have been shown to be poor indicators with which to assess the acute care needs of older patients presenting with unspecific complaints [19-21]. The importance of sex when evaluating vital signs is also unclear, and there are ambiguous results regarding differences in assessment and treatment between males and females for different types of conditions [16, 22]. Swedish legislation requires that health care providers perform continuous follow-up on the planning, execution, outcomes, and improvement of their services [23]. Despite these requirements, the guidelines and protocols in Sweden are heterogeneous, based on best practices and not validated for the EMS context [24]. Nonconveyance decisions are complex, and the corresponding guidelines have shown questionable accuracy in determining appropriate care levels for non-conveyed patients [14, 25-27].
To develop practices with higher level of patient safety, some studies have highlighted the need for further insights into the characteristics of the non-conveyed population $[13,16]$. This study is part of a larger project called nonconveyance - go to other level of care (No-Go).

\section{Aim}

The primary aim of this study was to describe and compare the proportion and characteristics of non-conveyed EMS patients, together with assignment data.

The secondary aim of this study was to describe if there were any differences between male and female sex.

\section{Methods \\ Design}

This study used a descriptive and comparative consecutive cohort design. The report follows the Strengthening the Reporting of Observational Studies in Epidemiology (STROBE) guidelines [28].

\section{Setting and context}

The study was conducted in a region in central Sweden. The region contains three ambulance departments and three hospitals comprising one level I trauma centre and two smaller hospitals with limited intensive care unit (ICU) capacity. Twelve ambulances operate around the clock in the region, and an additional four ambulances are staffed during the daytime. These ambulances serve 295,000 inhabitants and receive approximately 30,000 assignments per year. The proportions of male and female inhabitants in the region were approximately equal in 2016, and the age-group distribution was as follows: 010 years, $12 \%$; $11-17$ years, $8 \%$; $18-30$ years, $17 \%$; $31-45$ years, $18 \%$; $46-64$ years, $23 \%$; $65-80$ years, $17 \%$; and $>80$ years, 5\% [29].

In Sweden, registered nurses (RNs) have 3 years of education at the university level, and RN specialists have an additional year of higher education. Since 2005, Swedish regulations have required ambulances to be staffed with health care professionals who are authorized to prepare and administer drugs [30]. In practice, the law requires each EMS team in Sweden to include at least one RN who can administer drugs and be responsible for the provided care. In addition to the RN with or without a specialist education, an EMS team may include another RN, a specialist ambulance nurse, or an emergency medical technician (EMT) [31]. There is no national requirement to staff ambulances with RNs specializing in prehospital emergency care, although approximately $60 \%$ of all EMS clinicians in the studied region were specialized ambulance nurses. RNs and EMTs also worked within the regional EMS system. Among all EMS clinicians, 1/3 were women. During summertime, the number of substitute EMTs increases 
due to holidays and a shortage of RNs. In this study, EMS personnel in general are referred to as EMS clinicians.

In 2015, the studied region implemented nonconveyance guidelines that were restrictive in their design, enabling EMS clinicians to choose not to convey patients and, instead, to refer them to levels of care other than ambulance care during transport to the ED. The guidelines included a triage system, the Rapid Emergency Triage and Treatment System (RETTS), which contains both Emergency Signs and Symptoms (ESS) codes and vital signs [32, 33]. Additionally, the nonconveyance guidelines include exclusion criteria built on expert consensus, summarized in a checklist (Additional file 1 - Exclusion criteria for non-conveyance). RETTS was developed in Sweden for the ED and is not validated for prehospital assessments or non-conveyance decisions.

The triage system uses the patient's main complaint, a description of the illness, and the signs and symptoms to assign the patient a specific ESS code and triage level. The studied region used a subset of ESS codes that did not include psychiatric disorders. The system triages patients into urgency levels and the time within which the patient should be assessed by a physician. The triage system has colour codes to indicate different urgency levels. Green and yellow are the lowest priority levels, meaning that the patient does not need immediate emergency care and can wait $3 \mathrm{~h}$ or more. The orange priority level means that the patient has urgent medical needs but can wait up to $20 \mathrm{~min}$ to be seen by a physician after the handover at the ED. Red indicates the highest priority level, meaning that the patient needs immediate care and assessment by a physician [32, 33].

EMS clinicians have the option to consult a physician at the receiving hospital for advice when making a nonconveyance decision. EMS clinicians can arrange an appointment at a health care facility and arrange for public transport either to the ED or to another health care facility. When a patient is not conveyed, a nonconveyance document is created and given to the patient. The document contains information about the assessment of the patient, decisions regarding further health care contact, and where the patient should turn in case the condition worsens. A non-conveyed patient could be advised to provide self-care at home, to seek primary health care, or to go to the ED via personal or public transport (Fig. 1).

EMS clinicians perform a structured patient interview according to the Advanced Medical Life Support concept [34], assessing vital signs such as cognition Reaction Level Scale (RLS) [35], respiratory rate (breaths/min), blood oxygen saturation $(\mathrm{SpO} 2)$, pulse (beats/min), blood pressure (mmHg), and temperature (degrees Celsius). For patients to be considered for non-conveyance, all vital signs should be in the normal range (Additional file 2 - Normal vital signs); additionally, children should have an ESS colour code of green, and adults should have a code of green or yellow. The patient or legal guardian must be able to communicate and understand the decision and information provided, and the patient must not need any drug administration, supervision or monitoring during transport to a health care facility (Additional file 1 - Exclusion criteria for non-conveyance).

\section{Sample and data collection}

All patients, including children and adults, who were visited by EMS from February 2016 to January 2017 but were not conveyed by the ambulance service were eligible for inclusion (Fig. 2). The data consisted of handwritten prehospital medical record data produced by EMS when patients were not conveyed. Data entry was structured a priori in SPSS version 25 with guidance and limitation instructions to ensure data quality. Data

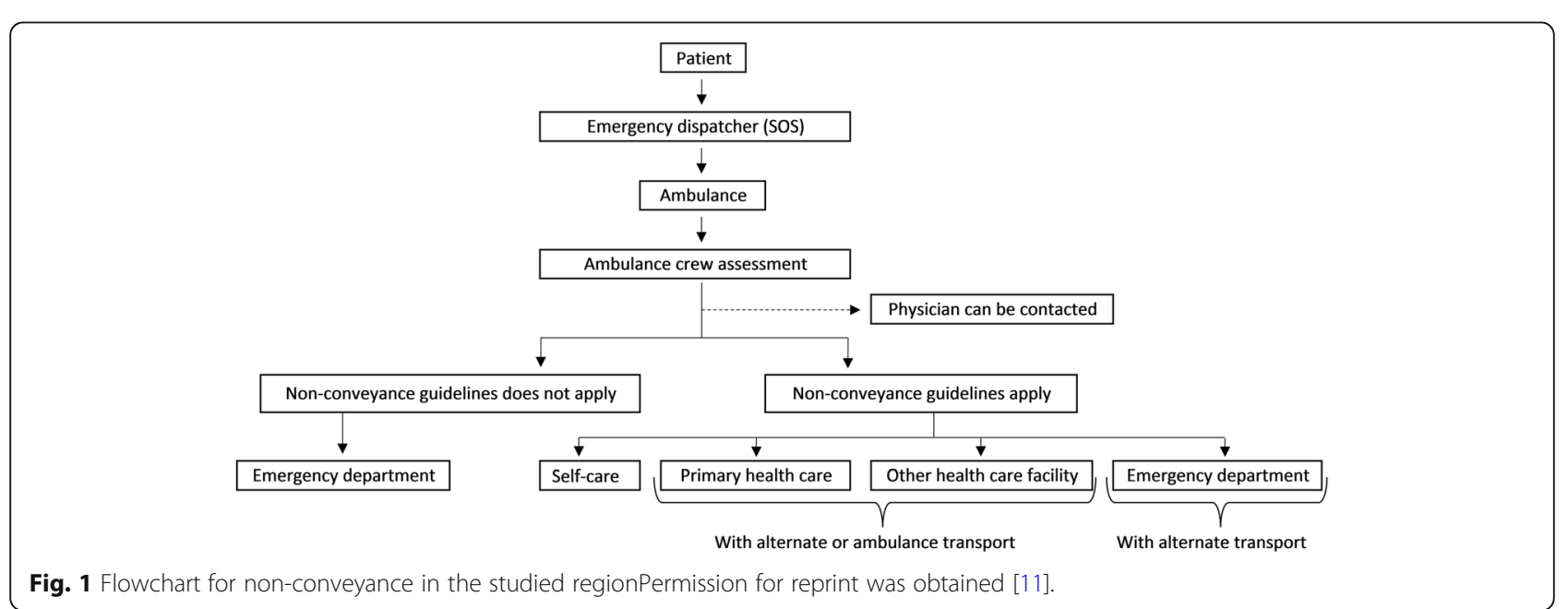






quality was checked both during and after entry. In total, $30 \%$ of all entered values were randomly selected and manually double-checked to verify that there were < $0.25 \%$ initial typographical errors. Typographical errors and deviant data were corrected.

We included all patients (children and adults) for whom the EMS clinician chose non-conveyance according to the guidelines.

We excluded all patients who refused care or ambulance conveyance as well as patients who were dead on the scene. See the inclusion and exclusion flowchart (Fig. 2).

\section{Data analysis}

Demographic data were analysed using descriptive statistics. Categorical variables were described as numbers and percentages and continuous variables as both median, Q1-Q3 and mean, standard deviation (SD).

The data were tested for an approximately normal distribution by both graphical and numerical methods, including, box plots, histograms, and the Shapiro-Wilk test. Mann-Whitneys U-test and Two-sample t test was used for continuous data. The chi-squared and proportion test were used for categorical variables.

A $p$-value threshold of $<0.05$ was used to test for statistical significance, and the Bonferroni correction was used for comparisons among $>5$ groups.

The variables of respiratory rate, pulse, and temperature are dependent on age and were therefore reported as low, normal or high instead of as their actual values; see additional file 2 . The last measured vital signs that formed the final triage was used in the analysis. Age groups were chosen to reflect on different stages of life and from nonconveyance guideline cut-offs between children and adults. Variables that were available for fewer than ten patients were not analysed. Data were analysed using
STATA 15.1 data analysis software (College Station, Texas, USA: Stata Corp) and IBM SPSS Statistics for Windows, Version 24.0 (Armonk, NY: IBM Corp).

\section{Results}

Patient characteristics and ambulance utilization

In relation to the 23,250 patients served by the EMS, 2691 (12\%) were not conveyed. The proportions of males and females were equal among the non-conveyed patients $(p=0.60)$. There was a statistically significant difference in non-conveyance rates across age groups $(p<0.001)$. There was a statistically significant difference for Age between non-conveyed male and female patients $(p<0.01)$. No statistically significant difference was found between males and females for Age groups, Day of week or Time of day. Most non-conveyance decisions were made in the evening, outside of office hours (Table 1).

Patients were non-conveyed from all different ages between 0 and 99 years of age (Fig. 3).

\section{Vital signs of non-conveyed patients}

For adult patients, vital signs were almost identical between males and females. There was a statistically significant difference $(P<0.01)$ for temperature and blood oxygen saturation between non-conveyed male and female adults. Patients' vital signs were mostly within the normal range. Notably, although EMS clinicians are required to collect all data needed for a complete triage according to RETTS, between 6 and 19\% of those data were incomplete. Between 1 and 14\% of recorded data for non-conveyed patients were outside the guideline recommendations for non-conveyance. The vital signs that deviated most from normal were blood oxygen saturation $\left(\mathrm{SpO}_{2}\right)$, with $14 \%$ of all recorded values between 90 and $95 \%$ (Table 2). 
Table 1 Patient characteristics and ambulance utilization, $n(\%)$ if not otherwise stated

\begin{tabular}{|c|c|c|c|}
\hline & Non-conveyed patients, $n=2691$ & Male $^{a}, n=1344$ & Female $^{a}, n=1317$ \\
\hline Age, Median (Q1-Q3) & $51(25-73)$ & $50(25-72)$ & $53(26-77)$ \\
\hline \multicolumn{4}{|l|}{ Age groups } \\
\hline $0-10$ years & $271(10)$ & $156(12)$ & $107(8)$ \\
\hline $11-17$ years & $115(4)$ & $52(4)$ & $57(4)$ \\
\hline 18-30 years & $471(18)$ & $236(18)$ & $223(17)$ \\
\hline $31-45$ years & $329(12)$ & $160(12)$ & $168(13)$ \\
\hline $46-64$ years & $492(18)$ & $261(19)$ & $228(17)$ \\
\hline $65-80$ years & $575(21)$ & $302(22)$ & $273(21)$ \\
\hline$>80$ years & $438(16)$ & $177(13)$ & $261(20)$ \\
\hline \multicolumn{4}{|l|}{ Day of week } \\
\hline Monday & $390(15)$ & $202(15)$ & $185(14)$ \\
\hline Tuesday & $387(14)$ & $190(14)$ & $195(15)$ \\
\hline Wednesday & $350(13)$ & $164(12)$ & $181(14)$ \\
\hline Thursday & $351(13)$ & $173(13)$ & $174(13)$ \\
\hline Friday & $375(14)$ & $191(14)$ & $180(14)$ \\
\hline Saturday & $450(17)$ & $230(17)$ & $216(16)$ \\
\hline Sunday & $388(14)$ & $194(14)$ & $186(14)$ \\
\hline \multicolumn{4}{|l|}{ Time of day } \\
\hline 00:00-07:59 & $585(22)$ & $294(22)$ & $287(22)$ \\
\hline 08:00-15:59 & $913(34)$ & 439 (33) & $466(35)$ \\
\hline 16:00-23:59 & $1167(43)$ & $594(44)$ & $555(42)$ \\
\hline
\end{tabular}

$P$-value $<0.05$ between non-conveyed male and female patients.

For $>5$ groups, the Bonferroni correction was used, $p<0.007$.

Mann-Whitneys U-test: Age. Proportion test: Sex.

Chi-squared test: Age groups, Day of week and Time of day.

${ }^{a}$ Sex missing 30 values, ${ }^{b}$ Time of day missing 26 values

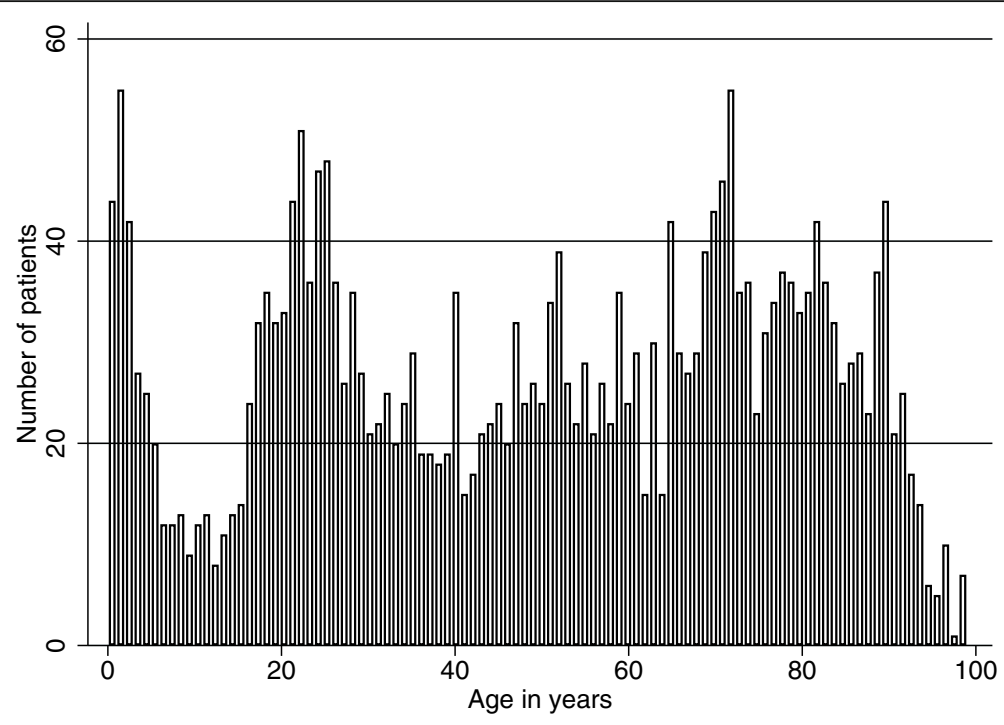

Fig. 3 Frequency histogram showing the number of non-conveyance patients from February 2016 to January 2017 
Table 2 Vital signs of non-conveyed adults ( $\geq 18$ years), $n$ (\%) if not otherwise stated

\begin{tabular}{|c|c|c|c|}
\hline & Non-conveyed patients, $n=2305$ & Male, $n=1136$ & Female, $n=1153$ \\
\hline \multicolumn{4}{|l|}{ Cognition } \\
\hline 1 & 2085 (99) & $1004(99)$ & 1067 (99) \\
\hline$\geq 2$ & $16(1)$ & $9(1)$ & $7(1)$ \\
\hline Missing & (9) & (11) & (7) \\
\hline Respiratory rate, Mean (SD) & $18(3)$ & $18(3)$ & $18(3)$ \\
\hline $8-25$ & $2083(100)$ & $1012(100)$ & $1052(99)$ \\
\hline$>30$ or $\leq 7$ & $1(<1)$ & $0(0)$ & $1(<1)$ \\
\hline $26-30$ & $9(<1)$ & $3(<1)$ & $5(<1)$ \\
\hline Missing & (9) & (11) & (8) \\
\hline Blood oxygen saturation, Mean (SD) & $98(2)$ & $97(2)$ & $98(2)$ \\
\hline $96-100$ & $1851(86)$ & $896(85)$ & $941(86)$ \\
\hline $90-95$ & $296(14)$ & $151(14)$ & $145(13)$ \\
\hline$<90$ & $5(<1)$ & $1(<1)$ & $4(<1)$ \\
\hline Missing & (7) & (8) & $63(5)$ \\
\hline Systolic blood pressure, Mean (SD) & $140(23)$ & $139(22)$ & $140(24)$ \\
\hline 90-199 & $2054(98)$ & $1004(99)$ & $1037(98)$ \\
\hline$\geq 200$ & $35(2)$ & $14(1)$ & $21(2)$ \\
\hline$<90$ & $1(<1)$ & $0(0)$ & $1(<1)$ \\
\hline Missing & (9) & (10) & (8) \\
\hline Diastolic blood pressure, Mean (SD) & $82(12)$ & $82(13)$ & $81(13)$ \\
\hline $40-100$ & $1784(96)$ & $866(95)$ & $905(96)$ \\
\hline$>100$ & $83(4)$ & $47(5)$ & $36(4)$ \\
\hline$<40$ & $0(0)$ & $0(0)$ & $0(0)$ \\
\hline Missing & (19) & (20) & (18) \\
\hline Pulse, Mean (SD) & $86(16)$ & $85(16)$ & $87(15)$ \\
\hline $50-120$ & $2137(99)$ & $1042(99)$ & $1081(99)$ \\
\hline$>120$ & $18(1)$ & $12(1)$ & $6(1)$ \\
\hline$<50$ & $4(<1)$ & $1(<1)$ & $3(<1)$ \\
\hline Missing & (6) & (7) & (5) \\
\hline Temperature, Mean (SD) & $37(1)$ & $37(1)$ & $37(1)$ \\
\hline $35-38.5$ & $1959(97)$ & 943 (97) & $1004(98)$ \\
\hline$>38.5$ & $39(2)$ & $21(2)$ & $17(2)$ \\
\hline$<35.0$ & $14(1)$ & $7(1)$ & $7(1)$ \\
\hline Missing & (13) & (15) & $125(11)$ \\
\hline
\end{tabular}

$P$-value $<0.05$ between non-conveyed male and female adults.

Mann-Whitneys U-test: Cognition. T-test: All other vital signs.

Vital signs for children (Table 3) showed that the majority were within the normal range. Pulse and respiratory rate were the vital signs deviating most from normal, with one in five triaged patients outside the normal range for each of those variables (Additional file 2 - Normal vital signs). There was a statistically significant difference $(P<0.01)$ for Diastolic blood pressure between non-conveyed male and female children.

\section{ESS coding and colours}

One in five of the adult patients were assigned the ESS code for unspecific symptoms/malaise. Most (97\%) had an ESS colour, which allowed them to be non-conveyed according to the non-conveyance guideline. ESS codes were represented in similar proportions for males and females (Table 4). No statistically significant difference was found between males and females for ESS codes or ESS colours $p>0.64$. 
Table 3 Vital signs of non-conveyed children (0-17 years), n (\%) if not otherwise stated

\begin{tabular}{|c|c|c|c|}
\hline & Non-conveyed patients, $n=386$ & Male, $n=208$ & Female, $n=164$ \\
\hline \multicolumn{4}{|l|}{ Cognition } \\
\hline 1 & $331(100)$ & $182(100)$ & $140(100)$ \\
\hline$\geq 2$ & $0(0)$ & $0(0)$ & $0(0)$ \\
\hline Missing & (14) & (13) & (15) \\
\hline Respiratory rate, Mean (SD) & $25(10)$ & $25(10)$ & $25(9)$ \\
\hline Normal & $267(78)$ & $147(79)$ & $112(77)$ \\
\hline High & $73(21)$ & $37(20)$ & $33(23)$ \\
\hline Low & $2(1)$ & $1(1)$ & $1(1)$ \\
\hline Missing & (11) & (11) & (11) \\
\hline Blood oxygen saturation, Mean (SD) & $99(1)$ & $99(1)$ & $99(1)$ \\
\hline $96-100$ & $310(97)$ & $168(97)$ & $132(96)$ \\
\hline $90-95$ & $11(3)$ & $6(3)$ & $5(4)$ \\
\hline$<90$ & $0(0)$ & $0(0)$ & $0(0)$ \\
\hline Missing & (17) & (16) & (15) \\
\hline Systolic blood pressure, Mean (SD) & $121(16)$ & $121(16)$ & $120(14)$ \\
\hline $90-199$ & $108(100)$ & $50(100)$ & $54(100)$ \\
\hline Missing & (72) & (76) & (67) \\
\hline Diastolic blood pressure, Mean (SD) & $75(11)$ & $71(11)$ & $78(11)$ \\
\hline $50-120$ & $89(100)$ & $42(100)$ & $43(100)$ \\
\hline Missing & $(77)$ & (80) & (74) \\
\hline Pulse, Mean (SD) & $114(26)$ & $114(25)$ & $114(28)$ \\
\hline Normal & $251(76)$ & $143(80)$ & $101(72)$ \\
\hline High & $74(22)$ & $34(19)$ & $38(27)$ \\
\hline Low & $4(1)$ & $2(1)$ & $2(1)$ \\
\hline Missing & $(15)$ & (14) & (14) \\
\hline Temperature, Mean (SD) & $37(1)$ & $37(1)$ & $38(1)$ \\
\hline Normal & $302(100)$ & $162(100)$ & $131(100)$ \\
\hline High & $0(0)$ & $0(0)$ & $0(0)$ \\
\hline Low & $1(<1)$ & $1(<1)$ & $0(0)$ \\
\hline Missing & $(22)$ & (22) & (20) \\
\hline
\end{tabular}

$P$-value $<0.05$ between non-conveyed male and female children.

Mann-Whitneys U-test: Cognition. T-test: All other vital signs.

Table 5 shows that the ESS codes for almost one-third of the children were missing (missing document or not documented by the EMS clinicians); this category was more common than any single ESS code. Breathing difficulties and fever of unclear origin were the most commonly used ESS codes for children, representing $25 \%$ of all used ESS codes. No statistically significant difference was found between males and females for ESS codes or ESS colours $p>0.29$.

In total, 1699 people had a designated non-conveyance level of care, of whom 329 were transported to the ED by some means other than an ambulance (19\%), 496 were referred to primary health care (29\%), and 874 were discharged for self-care (51\%). For both children and adults, there were no significant differences between males and females (all $p>0.05$ ) in the frequency of any non-conveyance destination. Children's (0-17 years) non-conveyance destinations were similar to those of adults (Table 6).

\section{Discussion}

The primary aim of this study was to describe the proportion and characteristics of non-conveyed EMS patients, together with assignment data.

This study showed that approximately $12 \%$ of EMS patients in the studied region were not conveyed. This rate is lower than international non-conveyance rates [4, 7]. This difference could relate to structural and contextual 
Table 4 ESS codes and colours for non-conveyed adults ( $\geq 18$ years), n (\%) if not otherwise stated

\begin{tabular}{|c|c|c|c|}
\hline & Non-conveyed patients, $n=2305$ & Male, $n=1136$ & Female, $n=1153$ \\
\hline \multicolumn{4}{|l|}{ ESS code } \\
\hline 53 - Unspecific symptoms, malaise & $345(20)$ & $169(20)$ & $175(20)$ \\
\hline 6 - Abdomen, flank or groin pain & $173(10)$ & $77(9)$ & $95(11)$ \\
\hline 4 - Breathing difficulties & $136(8)$ & $49(6)$ & $86(10)$ \\
\hline 5 - Chest pain & $99(6)$ & $46(5)$ & $52(6)$ \\
\hline 11 - Vertigo, balance problems & $97(6)$ & $40(5)$ & $57(6)$ \\
\hline 50 - Hypoglycaemia & $84(5)$ & $44(5)$ & $40(5)$ \\
\hline 20 - Loss of consciousness & $74(4)$ & $37(4)$ & $37(4)$ \\
\hline 40 - Intoxication & $62(4)$ & $38(5)$ & $24(3)$ \\
\hline 47 - Fever, infection & $59(3)$ & $26(3)$ & $31(4)$ \\
\hline 14 - Back or neck pain & $57(3)$ & $27(3)$ & $30(3)$ \\
\hline All other ESS-codes & $56(3)$ & $29(3)$ & $27(3)$ \\
\hline 30 - Injury, head/neck, strangulation, teeth & $52(3)$ & $31(4)$ & $20(2)$ \\
\hline 34 - Injury, legs/lower extremities & $49(3)$ & $30(4)$ & $20(2)$ \\
\hline 3 - Haemoptysis, epistaxis & $45(3)$ & $24(3)$ & $21(2)$ \\
\hline 19 - Headache, neuralgia & $41(2)$ & $18(2)$ & $22(3)$ \\
\hline 1 - Irregular heartbeat & $39(2)$ & $19(2)$ & $20(2)$ \\
\hline 9 - Seizures, epilepsy & 38 2) & $18(3)$ & $10(1)$ \\
\hline 33 - Injury, shoulder/collarbone/arm/hand & $38(2)$ & $22(3)$ & $15(2)$ \\
\hline 15 - Extremity problems/pain & $36(2)$ & $10(1)$ & $26(3)$ \\
\hline 43 - Allergy & $33(2)$ & $10(1)$ & $23(3)$ \\
\hline 31 - Injury, abdomen/thorax/genitalia & $29(2)$ & $21(3)$ & $<10$ \\
\hline 12 - Neurological problems & $27(2)$ & $12(1)$ & $15(2)$ \\
\hline 16 - Urinary problems/pain & $20(1)$ & $15(2)$ & $26(3)$ \\
\hline 21 - Pregnancy and related problems & $15(1)$ & $<10$ & $15(2)$ \\
\hline 49 - Diabetes, high blood sugar & $14(1)$ & $<10$ & $<10$ \\
\hline 35 - Electrical/chemical accident & $11(1)$ & $<10$ & $<10$ \\
\hline 41 - Animal bites and toxic effects & $11(1)$ & $<10$ & $<10$ \\
\hline Missing & (24) & (26) & (22) \\
\hline \multicolumn{4}{|l|}{ ESS colour } \\
\hline Green & $1172(72)$ & $552(72)$ & $610(71)$ \\
\hline Yellow & $416(25)$ & $198(26)$ & $218(26)$ \\
\hline Orange/Red & $46(3)$ & $20(2)$ & $26(3)$ \\
\hline Missing & (29) & (31) & (26) \\
\hline
\end{tabular}

$P$-value $<0.05$ between males and females. The Bonferroni correction was used, $p<0.002$.

The chi-squared test was used to test statistical significance.

differences between EMS systems and how nonconveyance is measured and recorded. For instance, the regional non-conveyance guidelines give EMS clinicians the option to disregard the guidelines if the ambulance nurse feels uncertain about the non-conveyance decision; in this case, the patient may be conveyed even if all other non-conveyance criteria are met.

For adult patients, unspecific symptoms/malaise, abdomen/flank/groin pain and breathing difficulties were the three most commonly used ESS codes documented by the EMS clinician. There are differences between different EMS systems regarding non-conveyed patients' primary reasons for contacting EMS. For instance, Vloet et al. [16] showed in another context that non-conveyed patients most commonly contacted the EMS due to problems with the circulatory system; injuries; poisoning; and mental, behavioural and neurodevelopmental disorders. To be able to compare and build on previous 
Table 5 ESS codes and colours for non-conveyed children (0-17 years), n (\%) if not otherwise stated

\begin{tabular}{|c|c|c|c|}
\hline Children ( $0-17$ years) & Non-conveyed patients, $n=386$ & Male, $n=208$ & Female, $n=164$ \\
\hline \multicolumn{4}{|l|}{ ESS code } \\
\hline 104 - Breathing difficulties & $41(15)$ & $28(18)$ & $12(11)$ \\
\hline 154 - Fever of unclear origin & $28(10)$ & $16(10)$ & $10(9)$ \\
\hline 130 - Injury, head/neck, strangulation, teeth & $24(9)$ & $16(10)$ & $8(7)$ \\
\hline 109 - Seizures, epilepsy & $20(7)$ & $11(7)$ & $9(8)$ \\
\hline 143 - Allergy & $15(5)$ & $11(7)$ & $3(3)$ \\
\hline 106 - Abdomen, flank or groin pain & $14(5)$ & $10(6)$ & $4(4)$ \\
\hline 144 - Mouth blisters, sore throat, cold & $14(5)$ & $9(6)$ & $5(4)$ \\
\hline 146 - Foreign object in nose, airway, ear, internal tracts & $13(5)$ & $5(3)$ & $8(7)$ \\
\hline 153 - Unspecific symptoms, worried parents & $12(4)$ & $5(3)$ & $7(6)$ \\
\hline 147 - Dermal or dental infection or lump & $10(4)$ & $6(4)$ & $4(4)$ \\
\hline Missing & (29) & (26) & (31) \\
\hline \multicolumn{4}{|l|}{ ESS colour } \\
\hline Green & $194(79)$ & $102(75)$ & $87(84)$ \\
\hline Yellow & $52(21)$ & $34(25)$ & $17(16)$ \\
\hline Orange/Red & $0(0)$ & $0(0)$ & $0(0)$ \\
\hline Missing & (36) & (35) & (37) \\
\hline
\end{tabular}

$P$-value $<0.05$ between males and females. The Bonferroni correction was used, $p<0.005$.

The chi-squared test was used to test statistical significance.

knowledge, it is important that guidelines and definitions are uniform within and between EMS systems.

In this study, decisions by EMS not to convey patients were not always compatible with the guidelines. Adherence to guidelines in the context of EMS has been shown to be moderate. With adherence to clinical guidelines between 8 and 95\%, among which monitoring recommendations are obeyed more frequently than treatment recommendations [36, 37]. The adherence issues could relate to the formats of the guidelines, which make them difficult to use in a prehospital setting $[24,36]$. Patient- and organization-related factors such as age, sex, comorbidities, location and education level have also been reported to influence adherence [36].

Patients do not always receive timely treatment due to non-conveyance decisions. Missing data caused by a lack of adherence could cause problems in conducting patient safety evaluations. It is not clear whether adherence issues involving incomplete triage and missing vital signs cause patient safety risks [12, 38, 39]. Adherence to clinical guidelines might improve if measures were taken to clarify for what purpose the guidelines are used and for

Table 6 Non-conveyance destination, $\mathrm{n}(\%)$ if not otherwise stated

\begin{tabular}{|c|c|c|c|}
\hline Adults ( $\geq 18$ years) & Non-conveyed patients, $n=2305$ & Male, $n=1136$ & Female, $n=1153$ \\
\hline \multicolumn{4}{|l|}{ Non-conveyance destination } \\
\hline Self-care & $746(51)$ & $367(52)$ & $432(51)$ \\
\hline Primary health care & $441(30)$ & $199(28)$ & $262(31)$ \\
\hline Emergency department & $275(19)$ & $134(19)$ & $155(18)$ \\
\hline Missing & (37) & (38) & $304(26)$ \\
\hline Children (0-17 years) & Non-conveyed patients, $n=386$ & Male, $n=208$ & Female, $n=164$ \\
\hline \multicolumn{4}{|l|}{ Non-conveyance destination } \\
\hline Self-care & $128(54)$ & $67(54)$ & $58(57)$ \\
\hline Primary health care & $55(23)$ & $25(20)$ & $25(25)$ \\
\hline Emergency department & $54(23)$ & $33(26)$ & $18(18)$ \\
\hline Missing & (39) & $(40)$ & $63(38)$ \\
\hline
\end{tabular}

$P$-value $<0.05$ between males and females.

The chi-squared test was used to test statistical significance.

Emergency department and primary health care is a non-conveyance destination via personal or public transport. 
what purpose medical record data are entered [40]. A digital medical record system with mandatory fields and checkboxes could also potentially mitigate the problem.

To be able to make these complex non-conveyance decisions [11] and follow Swedish legislation [23], ambulance organizations must implement validated guidelines and follow-up systems.

Descriptive studies of the non-conveyance population are beginning to clarify the characteristics of these patients, and further studies are needed to evaluate whether non-conveyance involves patient safety risks, since previous studies have shown contradictory results $[25,26]$.

For the results to be transferred to other settings, organizational structure, competence, education, transport distances, non-conveyance guidelines, outcome measures, and outcome measure definitions must be taken into consideration.

\section{Conclusions}

Fewer patients were non-conveyed in the studied region compared to national and international non-conveyance rates. There were no clinically relevant differences between sexes in the non-conveyed patient cohort. Some patients with abnormal vital signs and/or missing ESS codes were not conveyed. This study contributes knowledge to the limited research on non-conveyed patients, and it provides information needed to develop validated guidelines that have the potential to enhance the ability of EMS to make patient-safe non-conveyance assessments.

To enhance patient safety, we need further information regarding patients who are not conveyed, in comparison with conveyed patients, in order to understand why they are not conveyed, where they are sent, and whether they experience negative consequences due to this practice. Further research is needed that describes and predicts the outcomes of non-conveyed patients. Predictive models could have the potential to find patients at risk of future deterioration when patients are non-conveyed.

\section{Limitations}

Information bias could distort the proportions of different ESS codes, since not all available codes were used in the studied region. For instance, this limited range of codes could affect the percentage of the ESS code "unspecific symptoms/malaise", since psychiatric disorders could have been sorted under this code. Since the research data were gathered within the limitations of the organizational structure and triage systems, it was not possible to adjust for this possibility when planning the study. The regional non-conveyance guidelines also give EMS clinicians the option to disregard the guidelines if the ambulance nurse feels uncertain about the nonconveyance decision; in this case, the ambulance may convey the patient even if all other non-conveyance criteria are met. Such departures from the guidelines could have affected the numbers and proportions of nonconveyed patients.

Missing data might also constitute a limitation of the study due to the risk of skewed data and misinterpreted results. Comparative information for conveyed patients was not available for the same period as non-conveyed patients.

\section{Supplementary information}

Supplementary information accompanies this paper at https://doi.org/10. 1186/s12873-020-00353-8.

Additional file 1. Exclusion criteria for non-conveyance.

Additional file 2. Normal vital signs.

\section{Abbreviations}

ED: Emergency department; EMS: Emergency medical services;

ESS: Emergency Signs and Symptoms; RETTS: Rapid Emergency Triage and

Treatment System; RN: Registered nurse

\section{Acknowledgements}

The authors thank the administrators at the University Health Care Research Center for creating the database.

\section{Authors' contributions}

Study design (EH, MA-H, AS, MM, EO-N). Data collection (EH). Data analysis (EH, MA-H, AS, MM, EO-N). Manuscript preparation (EH, MA-H, AS, MM, EO-N). All authors read and approved the final manuscript.

\section{Funding}

This research received funding support from the Research Committee in the county council of Örebro (grant numbers: OLL-674451, OLL-767301, OLL811401, OLL-840471). The funding body had no role in the design, collection, analysis, interpretation of data, or writing of the manuscript. Open access funding provided by Örebro University.

\section{Availability of data and materials}

The datasets generated and analysed during the current study are not publicly available due to patient privacy. The datasets used and analysed during the present study are available from the corresponding author $(\mathrm{EH})$ on reasonable request.

Ethics approval and consent to participate

This study follows the ethical principles of the Declaration of Helsinki [41] and received ethical approval from the regional review board in Uppsala, Sweden (Dnr: 2015/465; amendment Dnr: 2015/465/1, 3).

\section{Consent for publication}

Not applicable.

\section{Competing interests}

The authors declare that they have no competing interests.

\section{Author details}

${ }^{1}$ University Health Care Research Center, Faculty of Medicine and Health, Örebro University, Box 1613, 70116 Örebro, Sweden. ${ }^{2}$ Centre for Prehospital Research, Faculty of Caring Science, Work Life and Social Welfare, University of Borås, Borås, Sweden. ${ }^{3}$ Department of Health Sciences in Gjøvik, Faculty of Medicine and Health Sciences, NTNU - Norwegian University of Science and Technology, Gjøvik, Norway. ${ }^{4}$ Department of Surgery, Faculty of Medicine and Health, Örebro University, Örebro, Sweden. 
Received: 20 March 2020 Accepted: 21 July 2020

\section{Published online: 10 August 2020}

\section{References}

1. Andrew E, Nehme Z, Cameron P, Smith K. Drivers of increasing emergency ambulance demand. Prehosp Emerg Care. 2019. https://doi.org/10.1080/ 10903127.2019.1635670.

2. National Audit Office. NHS ambulance services [Report]. 2017. https://www. nao.org.uk/wp-content/uploads/2017/01/NHS-Ambulance-Services.pdf. Accessed 12 Nov 2019.

3. Hjalte L, Suserud BO, Herlitz J, Karlberg I. Why are people without medical needs transported by ambulance? A study of indications for pre-hospital care. Eur J Emerg Med. 2007;14:151-6.

4. Hoikka M, Silfvast T, Ala-Kokko TI. A high proportion of prehospital emergency patients are not transported by ambulance: a retrospective cohort study in northern Finland. Acta Anaesthesiol Scand. 2017:61:549-56.

5. Pekanoja S, Hoikka M, Kyngäs H, Elo S. Non-transport emergency medical service missions - a retrospective study based on medical charts. Acta Anaesthesiol Scand. 2018;62(5):701-8. https://doi.org/10.1111/aas.13071 Epub 2018 Jan 24. PMID: 29363100

6. Kawakami C, Ohshige K, Kubota K, Tochikubo O. Influence of socioeconomic factors on medically unnecessary ambulance calls. BMC Health Serv Res. 2007;7:120.

7. O'Cathain A, Knowles E, Bishop-Edwards L, Coster J, Crum A, Jacques R, et al. Understanding variation in ambulance service non-conveyance rates: a mixed methods study. Health Serv Deliv Res. 2018. https://doi.org/10.3310/ hsdr06190.

8. Lowthian JA, Cameron PA, Stoelwinder JU, Curtis A, Currell A, Cooke MW, et al. Increasing utilisation of emergency ambulances. Aust Health Rev. 2011;35:63-9.

9. Hjalte L, Suserud BO, Herlitz J, Karlberg I. Initial emergency medical dispatching and prehospital needs assessment: a prospective study of the Swedish ambulance service. Eur J Emerg Med. 2007;14:134-41.

10. Booker MJ, Shaw ARG, Purdy S. Why do patients with 'primary care sensitive' problems access ambulance services? A systematic mapping review of the literature. BMJ Open. 2015:5:e007726.

11. Hoglund E, Schroder A, Moller M, Andersson-Hagiwara M, Ohlsson-Nevo E. The ambulance nurse experiences of non-conveying patients. J Clin Nurs. 2018;28:235-44.

12. Hagiwara MA, Magnusson C, Herlitz J, Seffel E, Axelsson C, Munters M, et al. Adverse events in prehospital emergency care: a trigger tool study. BMC Emerg Med. 2019;19:14.

13. Ebben RHA, Vloet LCM, Speijers RF, Tonjes NW, Loef J, Pelgrim T, et al. A patient-safety and professional perspective on non-conveyance in ambulance care: a systematic review. Scand J Trauma Resusc Emerg Med. 2017;25:71.

14. Halter M, Vernon S, Snooks H, Porter A, Close J, Moore F, et al. Complexity of the decision-making process of ambulance staff for assessment and referral of older people who have fallen: a qualitative study. Emerg Med J. 2011:28:44-50

15. Simmonds RL, Shaw A, Purdy S. Factors influencing professional decision making on unplanned hospital admission: a qualitative study. $\mathrm{Br} J \mathrm{Gen}$ Pract. 2012;62:e750-6.

16. Vloet LCM, de Kreek A, van der Linden EMC, van Spijk JJA, Theunissen VAH, van Wanrooij $\mathrm{M}$, et al. A retrospective comparison between non-conveyed and conveyed patients in ambulance care. Scand J Trauma Resusc Emerg Med. 2018;26:91

17. Campbell NC, Iversen L, Farmer J, Guest C, MacDonald J. A qualitative study in rural and urban areas on whether - and how - to consult during routine and out of hours. BMC Fam Pract. 2006;7:26.

18. Beillon LM, Suserud BO, Karlberg I, Herlitz J. Does ambulance use differ between geographic areas? A survey of ambulance use in sparsely and densely populated areas. Am J Emerg Med. 2009;27(2):202-11.

19. Lucke JA, de Gelder J, Clarijs F, Heringhaus C, de Craen AJM, Fogteloo AJ, et al. Early prediction of hospital admission for emergency department patients: a comparison between patients younger or older than 70 years. Emerg Med J. 2018;35:18-27.

20. Chester JG, Rudolph JL. Vital signs in older patients: age-related changes. Am Med Dir Assoc. 2011;12:337-43.
21. Churpek MM, Yuen TC, Winslow C, Hall J, Edelson DP. Differences in vital signs between elderly and nonelderly patients prior to ward cardiac arrest. Crit Care Med. 2015;43:816-22.

22. Weiss SJ, Ernst AA, Phillips J, Hill B. Gender differences in state-wide EMS transports. Am J Emerg Med. 2000;18:666-70.

23. Swedish Government. Patientsäkerhetslag SFS 2010:6 59. [Patient Safety Act SFS 2010:659.]. Stockholm: Ministry of Health and Social Affairs; 2010.

24. Hagiwara MA, Suserud BO, Jonsson A, Henricson M. Exclusion of context knowledge in the development of prehospital guidelines: results produced by realistic evaluation. Scand J Trauma Resusc Emerg Med. 2013;21:46.

25. Breeman W, Poublon NA, Verhofstad MHJ, Van Lieshout EMM. Safety of onscene medical care by EMS nurses in non-transported patients: a prospective, observational study. Scand J Trauma Resusc Emerg Med. 2018:26:79.

26. Gray JT, Wardrope J. Introduction of non-transport guidelines into an ambulance service: a retrospective review. Emerg Med J. 2007:24:727-9.

27. Farrohknia N, Castren M, Ehrenberg A, Lind L, Oredsson S, Jonsson H, et al. Emergency department triage scales and their components: a systematic review of the scientific evidence. Scand J Trauma Resusc Emerg Med. 2011;19:42.

28. von Elm E, Altman DG, Egger M, Pocock SJ, Gotzsche PC, Vandenbroucke JP. Strengthening the reporting of observational studies in epidemiology (STROBE) statement: guidelines for reporting observational studies. BMJ. 2007:335:806-8.

29. Sweden S. Statistikdatabasen. Stockholm: SCB; 2016. http://www. statistikdatabasen.scb.se. Accessed 12 Dec 2019

30. National Board of Health and Welfare. Regulations and general recommendations for handling medicines in the health care system ("SOSFS2000:1. Socialstyrelsens föreskrifter och allmänna råd om läkemedelshantering i hälso- och sjukvården"). Stockholm: National Board of Health and Welfare; 2000.

31. Lindström V, Bohm K, Kurland L. Prehospital care in Sweden: from a transport organization to advanced healthcare. Notf Rett Med. 2015;18:107-9.

32. Larsson G, Holmen A, Ziegert K. Early prehospital assessment of non-urgent patients and outcomes at the appropriate level of care: a prospective exploratory study. Int Emerg Nurs. 2017;32:45-9.

33. Widgren B. RETTS: akutsjukvård direkt. Lund: Studentlitteratur; 2012.

34. Scotese B. Advanced medical life support: an assessment-based approach. Burlington: Jones \& Bartlett Learning; 2017. https:/www.worldcat.org/title/ advanced-medical-life-support-an-assessment-based-approach/oclc/949837880.

35. Walther SM, Jonasson U, Gill H. Comparison of the Glasgow coma scale and the reaction level scale for assessment of cerebral responsiveness in the critically ill. Intensive Care Med. 2003;29:933-8.

36. Ebben RH, Vloet LC, Verhofstad MH, Meijer S, Mintjes-de Groot JA, van Achterberg T. Adherence to guidelines and protocols in the prehospital and emergency care setting: a systematic review. Scand J Trauma Resusc Emerg Med. 2013;21:9

37. Magnusson C, Herlitz J, Karlsson T, Axelsson C. Initial assessment, level of care and outcome among children who were seen by emergency medical services: a prospective observational study. Scand J Trauma Resusc Emerg Med. 2018;26:88

38. Alsholm L, Axelsson C, Hagiwara MA, Niva M, Claesson L, Herlitz J, et al. Interrupted transport by the emergency medical service in stroke/transitory ischemic attack: a consequence of changed treatment routines in prehospital emergency care. Brain Behav. 2019;9:e01266.

39. Magnusson C, Axelsson C, Nilsson L, Stromsoe A, Munters M, Herlitz J, et al. The final assessment and its association with field assessment in patients who were transported by the emergency medical service. Scand J Trauma Resusc Emerg Med. 2018;26:111.

40. Ebben RHA, Siqeca F, Madsen UR, Vloet LCM, van Achterberg T. Effectiveness of implementation strategies for the improvement of guideline and protocol adherence in emergency care: a systematic review. BMJ Open. 2018:8:e017572.

41. World Medical Association. Declaration of Helsinki-ethical principles for medical research involving human subjects. 2013. https://pdf-it devacw. website/please-and-thank-you?url=https://www.wma.net/policies-post/wmadeclaration-of-helsinki-ethical-principles-for-medical-research-involvinghuman-subjects/\&pdfName=wma-declaration-of-helsinki-ethical-principlesfor-medical-research-involving-human-subjects. Accessed 3 Dec 2019.

\section{Publisher's Note}

Springer Nature remains neutral with regard to jurisdictional claims in published maps and institutional affiliations. 